\title{
Fatigue Analysis of Polyethylene Fuel Tanks Used in Buses
}

\author{
Vedat Z. Doğan, H. Burak Ustaoğlu, Serter Atamer, Gökay Simitçioğlu, Zahit Mecitoğlu, Halit S. Türkmen, \\ Erdem Akay, Sedat Süsler, Sena Ayhün, Y. Emre Erginsoy
}

\begin{abstract}
In this paper, the fatigue analysis part of a project which aims to develop a computer aided methodology for developing/designing of the polyethylene fuel tanks is presented. The fatigue performance of the polyethylene material based on the stress-life (S-N) approach is obtained by coupon tests. Dynamic "g forces", which act on the fuel tanks as base excitations, are obtained from the specific bad road runway experiments by the Mercedes-Benz Turk (MBT) R\&D Center. In the finite element simulation, dynamic stresses are obtained for different fullness ratios of the tank by using PERMAS V15. Fluid-structure interaction problem is also considered, fluid (fuel) is modeled with acoustic elements, and structure (tank) is modeled with shell elements. Fatigue life prediction of the fuel tank is conducted by using the FEMFAT (Finite Element Fatigue Analysis) program. After evaluating results, some geometry optimization is performed. Finally, all fatigue analysis results are compared with the hydro-pulse test results for validation.
\end{abstract}

Keywords - polyethylene, finite element method, fatigue

\section{Introduction}

Plastic fuel tanks instead of steel tanks have been used in recent years due to their several advantageous properties such as their light weight, low material and production costs, high safety levels, greater capacity due to greater choice of shape, non-corrosiveness property and good design flexibility In 1972, VW Passat cars with plastic fuel tanks were manufactured for the first time as a mass production. Since then the major automobile manufacturers around the world have started to show interest in and to work on the use of the plastic fuel tanks [1].

The effect of sloshing in a fuel tank is one of the most crucial problems for the fuel tank design, and, obviously, percentage of fullness influences sloshing effects. The sloshing in a partially full tank in the state of failure was investigated by Vytla et al [2]. In this study, there are two tanks filled up to $53 \%$ and $40 \%$, and two breaking events, a light one and a heavy one were investigated. The sloshing problem was solved by the fluid-solid interaction technique. Water is used instead of fuel. It is found that the sloshing level increases in the case of low percentage of fullness.

V .Z. Doğan, G. Simitçioğlu, Z. Mecitoğlu, H.S. Türkmen, E. Akay, S Süsler, S. Ayhün, Y.E. Erginsoy

Istanbul Technical University

Turkey

H.B. Ustaoğlu, S. Atamer

Mercedes-Benz Türk A.Ș.

Turkey
In other words, it takes time for a liquid to become calm and there is a high probability of fuel noise while the water percentage is lower. In another study, the fuel in a tank was modeled. After three fullness rates of $51 \mathrm{~L}, 42 \mathrm{~L}$ and $28 \mathrm{~L}$ were compared to each other, the $42 \mathrm{~L}$ of fuel fullness were found to cause the highest noise [3]. Himeki et al. made simulations using pressure variations in the fuel tank. The correlation between different factors (such as stress, temperature, frequency) and fatigue life is stated quantitatively by using fatigue test data for the test specimen. This statement then verified with fatigue tests applied on the fuel tank. So that the validity of equations used for the prediction of fatigue life of fuel tanks are verified. Consequently, fatigue life equations and finite elements method (FEM) can be used in design process to evaluate fatigue strength [4]. Yay and Ereke made S-N fatigue life analysis of a truck body using artificial road data. In this study, artificial road data representing real road conditions are produced and these data is applied to the chassis by using hydro-pulse device. Strains on the chassis are collected by using strain gages. These achieved signals are classified by rainflow counting algorithm and stress amplitude values in time domain are achieved. Stress amplitude values that are classified are used in damage calculation using Palmgren-Miner method. All the data achieved are processed for fatigue life to be computed [5].

Main purpose of this paper is to execute a fatigue analysis in order to find damage values on critical locations of the polyethylene fuel tank. For modelling the fuel acoustic methodology is used. Torture track signal is used as base excitation on the tank. Then, modal stresses and their participation factors are found from FE analyses of the fuel tank for different fullness ratios. The S-N curve used in fatigue analysis is evaluated from the tests conducted in Istanbul Technical University (ITU) Composite Structure Laboratory. This S-N curve data obtained from three point bending test is modified into tensile one. In this paper, fatigue analysis is performed using FEMFAT 5.1 ChanelMax module. Using all the information, geometry optimization process is conducted. In conclusion, ongoing hydro-pulse test results had been using for correlation of the damage values and fatigue life.

\section{Formulation}

\section{A. FE Formulation}

In acoustic fluid-structural interaction (FSI) problems, the structural dynamics equation must be considered along with the Navier-Stokes (momentum) equation and the continuity equation. The discretized structural dynamics equation can be formulated using the structural elements. The fluid momentum (Navier-Stokes) equations and 
continuity equations are simplified to get the acoustic wave equation as follows:

$\nabla \cdot\left(\frac{1}{\rho_{0}}, \nabla p\right)-\frac{1}{\rho_{0} c^{2}} \frac{\partial^{2} p}{\partial t^{2}}+\nabla \cdot\left[\frac{4 \mu}{3 \rho_{0}} \nabla\left(\frac{1}{\rho_{0} c^{2}} \frac{\partial p}{\partial t}\right)\right]=$ $-\frac{\partial}{\partial t}\left(\frac{Q}{\rho_{0}}\right)+\nabla \cdot\left[\frac{4 \mu}{3 \rho_{0}} \nabla\left(\frac{Q}{\rho_{0}}\right)\right]$

$$
c=\sqrt{\frac{K}{P_{0}}}
$$

Where,

- $\quad c=$ speed of sound in fluid medium

- $\quad \mathrm{p}=$ acoustic pressure $(=\mathrm{p}(\mathrm{x}, \mathrm{y}, \mathrm{z}, \mathrm{t}))$

- $\quad \rho_{\mathrm{o}}=$ mean fluid density

- $\mathrm{Q}=$ mass source in the continuity equation

- $\mathrm{K}=$ bulk modulus of fluid

- $\mathrm{t}=$ time

- $\mu=$ dynamic viscosity

In which the following assumptions are made:

- The fluid is incompressible

- $\quad$ There is no mean flow of the fluid.

The acoustic wave equation can be written in matrix notation. The discretized wave equation is given as follows [6].

\section{$\left[M_{F}\right]\left\{p_{\varepsilon}\right\}+\left[C_{F}\right]\left\{p_{\varepsilon}^{*}\right\}+\left[K_{F}\right]\left\{p_{\varepsilon}\right\}+\bar{p}_{0}[R]^{T}\left\{\tilde{u}_{F, \theta}\right\}=$ $\left\{f_{F}\right\}$}

\section{where}

- $\left[M_{F}\right]$ is acoustic fluid mass matrix

- $\left[C_{F}\right]$ is acoustic fluid damping matrix

- $\left[K_{F}\right]$ is acoustic fluid stiffness matrix

- $[R]^{T}$ is acoustic fluid boundary matrix

- $\left\{f_{F}\right\}$ is acoustic fluid load vector

- $\quad \overline{\rho_{0}}$ is acoustic fluid mass density constant and their definitions are given in Eqs. (4) to (8) [6].

$$
\begin{gathered}
\left.\left[M_{F}\right]=\bar{p}_{0} \iiint_{\Omega_{f}} \frac{1}{p_{0} c^{2}}\{N\} N\right\}^{T} d v \\
{\left[C_{F}\right]=\bar{p}_{0} \iiint_{\Omega_{f}}\left(\frac{4 \mu}{3 p_{0}{ }^{2} c^{2}}\right)[\nabla N]^{T}[\nabla N] d v}
\end{gathered}
$$

$$
\left\{f_{F}\right\}=\bar{p}_{0} \iiint_{\Omega_{f}} \frac{1}{\rho_{0}}\{N\}\{N\}^{T} d v\{\tilde{q}\}+\bar{p}_{0} \iiint_{\Omega_{f}}\left(\frac{4 \mu}{3 \rho_{0}{ }^{2}}\right)[\nabla N]^{T}[\nabla N] d v\{q\}
$$

\section{B. Modal Analyses}

Modal analyses are used to model the acoustic modes of an acoustic cavity (standing waves) or to compute the mode shapes of vibro-acoustic systems. For pure acoustics modal analyses the acoustic modes are computed using the following equation

$$
\left(-\omega^{2}\left[M_{f}\right]+j \omega\left[C_{f}\right]+\left[K_{f}\right]\right)\{p\}=0
$$

For fluid structure interaction problems, the acoustic and the structural coupled modes are computed using the following [6]

$$
\begin{aligned}
& \left(-\omega^{2}\left[\begin{array}{cc}
M_{g} & 0 \\
p_{0} R^{T} & M_{f}
\end{array}\right]+j \omega\left[\begin{array}{cc}
C_{g} & 0 \\
0 & C_{f}
\end{array}\right]+\right. \\
& \left.\left[\begin{array}{cc}
K_{g} & -R \\
0 & K_{f}
\end{array}\right]\right)\left\{\begin{array}{l}
u \\
\left.\frac{w}{p}\right\}=0
\end{array}\right.
\end{aligned}
$$

\section{Fatigue Formulation}

In fatigue analysis, $\mathrm{S}-\mathrm{N}$ total life method is used as the most common one. This method creates the relation between the total fatigue life and the elastic region stress values in whole section. Total life method can be used for plastics and noniron metal materials in elastic region. This method is also applicable in random vibration problems in structures.

The steps of the analysis are shown in Figure 1. In order to perform the fatigue analysis, the fuel tank FE model is solved by using PERMAS V15 solver. In these analyses modal transient analysis methodology is used. The modal stress resultants and their participation factors are achieved as an output. These values and S-N curve of the materials are used together as input for the fatigue analyses. Fatigue analyses of the fuel tank for different fullness rates are conducted and damage values are obtained. 


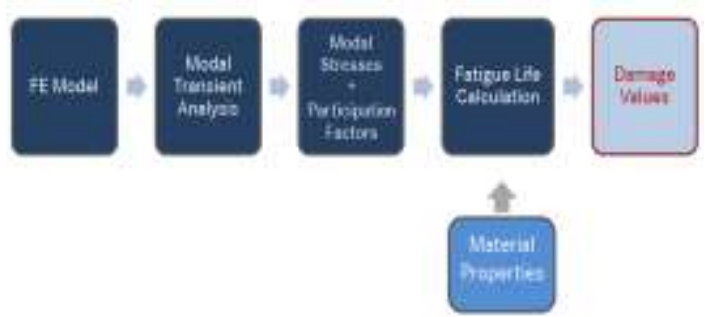

Figure 1. Fatigue analysis milestones.

A bending $\mathrm{S}-\mathrm{N}$ curve is generated from three-point bending coupon tests. This bending $\mathrm{S}-\mathrm{N}$ curve has to be modified to the tensile $\mathrm{S}-\mathrm{N}$ curve so as to get the accurate results from FEMFAT (Finite Element Fatigue Analysis program). Test results and modified S-N curve is explained in detail in "Fatigue Analysis Model of the tank and Material Properties of Polyethylene", Chapter III.

Palmgren-Miner fatigue life method sums the total damage up for each stress level. Equation (11) gives the damage for one stress level. Equation (12) gives the total damage as a sum of $\mathrm{k}$ different stress levels. When the total damage reaches to 1 , the structure is failed.

$$
\begin{gathered}
d_{\mathrm{i}}=\frac{n_{i}}{\mathbb{N}_{i}} \\
D=\sum_{i=1}^{k} d_{i}
\end{gathered}
$$

where $n_{i}$ is the number of accumulated cycles at $\mathrm{i}^{\text {th }}$ stress and $N_{i}$ is the number of cycles to failure at the $\mathrm{i}^{\text {th }}$ stress.

The continuation of S-N curve changes below certain stress amplitude values, which is differentiated with three approaches that are namely: Miner original, Miner elementary and Miner modified. In Miner original, load cycles below endurance limit does not have damage effect on the structure, which is not true for some structures. Miner elementary method is also a simplified approach like Miner original which indicates that no endurance limit exists that S-N curve has constant slope. This approach takes the damage effect of low stress amplitudes into account as same as high stress amplitudes.

In this study, minor modified approach is used. Minor modified approach can be seen as a compromise of two methods. In this approach slope of S-N curve is modified after the fatigue limit as $2 \mathrm{k}-1$ for ductile materials. This assumption neither takes the damage effect of low stresses as zero, nor as equal as high stress amplitudes, but it creates an accurate approach. The modifications of three approaches on S-N curve are shown in a Figure 2 [7].

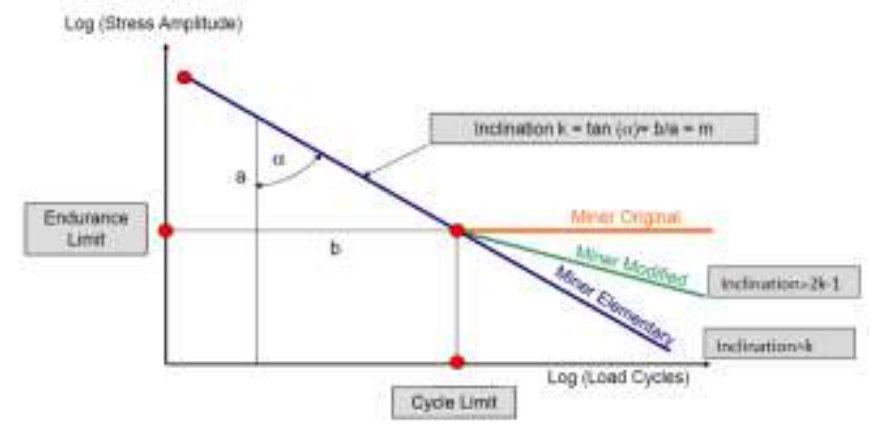

Figure 2. S-N curves of Miner approaches.

In the FEMFAT fatigue tool, some adjustments are done in order to obtain more reliable damage results. First; as stated before, minor modified approach is selected. Second, FEMFAT and similar programs calculate damages by creating critical planes in the structure and calculating stress amplitudes on these planes. While calculating these stresses it is possible to use various methods. Using the preliminary analyses and the suggestions from software support, we decided to use "Normal Stress in Critical Plane" option to gain paramount results. Since the liquid pressure affects in normal direction on the fuel tank, this option is also rational. Third; as indicated before, FE analyses executed by using the modal transient analysis methodology and from its nature, linear perturbation method is used so that any nonlinearity (such as material one) is not permitted. In order to take this effect into account in fatigue analysis PLAST option in FEMFAT is used. FEMFAT PLAST contains an algorithm to consider the material nonlinearity after FE analysis in damage calculation. In material linear analyses, where Hook's law holds, that is, stress is proportional to strain with constant modulus of elasticity. However, in analysis of some highly nonlinear materials like polyethylene, some modification can be done with NeuberHyperbola algorithm.

Neuber's method is used to estimate plastic stress-strain state in linear analysis, in order to reduce non-linear results. This method allows a conversion of elastic stress values obtained from FEM into corrected elastic-plastic region values. Neuber formulation mostly used if the stress values in linear FE analysis are above plastic deformation of the material, it converges this high linear stresses into the real elastic-plastic stress strain curve of material. This approximation is utilized in FEMFAT PLAST. The graphical image of Neuber-Hyperbola method is shown in Figure 3. The formulation of Neuber-Hyperbola is given as

$$
\varepsilon_{\max } \cdot \sigma_{\max }=K_{\mathrm{t}}^{2} \cdot \frac{\sigma_{m}^{2}}{E}
$$

where $\varepsilon_{\max } \sigma_{\max }$ are maximum stress and strain in plastic area, $\sigma_{n}$ is the nominal stress value, $K_{t}$ is the stress concentration factor, $E$ is Young's modulus of the material [8],[9]. 


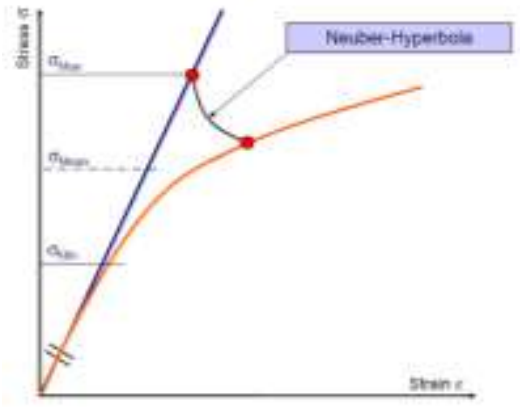

Figure 3. Neuber-Hyperbola representation.

\section{Fatigue Analysis Model and Material Properties of Polyethylene}

\section{A. Fatigue Analysis Model}

The base fuel tank model in the first step of the project with $7 \mathrm{~mm}$ wall thickness can be seen in Figure 4.

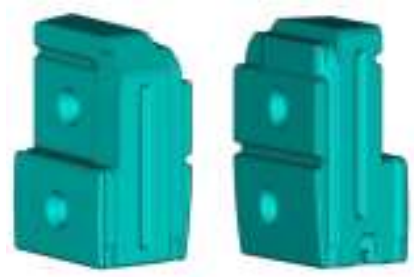

Figure 4. Base model.

After the early tests on the base model, fractures are noticed in two areas. The test rig and damages are shown in Figure 5.
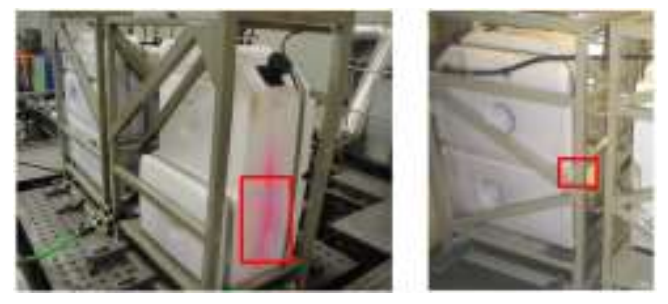

Figure 5. First and second crack regions.

As it can be seen in Figure 5, two critical areas are marked and we decided to concentrate on these two cracked regions in this study. To overcome these problems, first, a new fuel tank with $9 \mathrm{~mm}$ wall thickness is considered for tests and analyses. Using the Root Mean Square (RMS) values obtained from FE analyses, geometry optimization is performed. After some optimization loops, final tank model is shown in Figure 6.

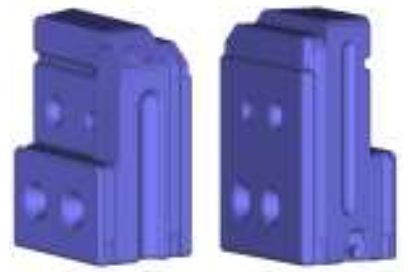

Figure 6. Final model.

\section{B. Obtaining S-N Curve}

Three point bending tests performed in order to obtain the S-N curve. However, FEMFAT software can only work accurately with the S-N curve derived from tensile fatigue testing. Therefore, a modification has to be done on the S-N curve. In order to do that; first, stress results are obtained by applying certain displacements on the fatigue test specimen shown in Figure 7 . With these known compressive and tensile stress values, fatigue analyses are performed by using FEMFAT BASIC module. These fatigue analyses are done by changing cycle values until to get the damage value as 1 . While doing this modification, survival probability is selected as \%50. Using cycle and stress amplitude values a new S-N curve is derived and fatigue analyses are repeated. As known; slope, endurance limit and cycle limit is necessary to define an S-N curve in FEMFAT. With modified cycle points, slope is optimized to pass the best curve. The previous and modified (red line) S-N curves are illustrated in Figure 8.

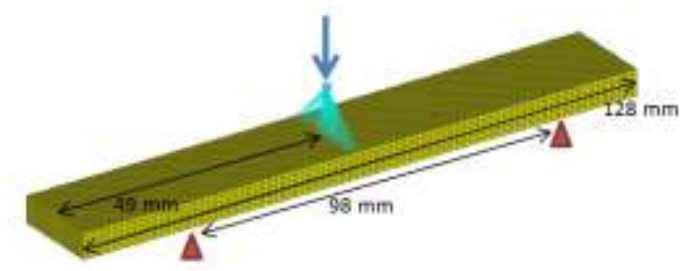

Figure 7. Fatigue test specimen.

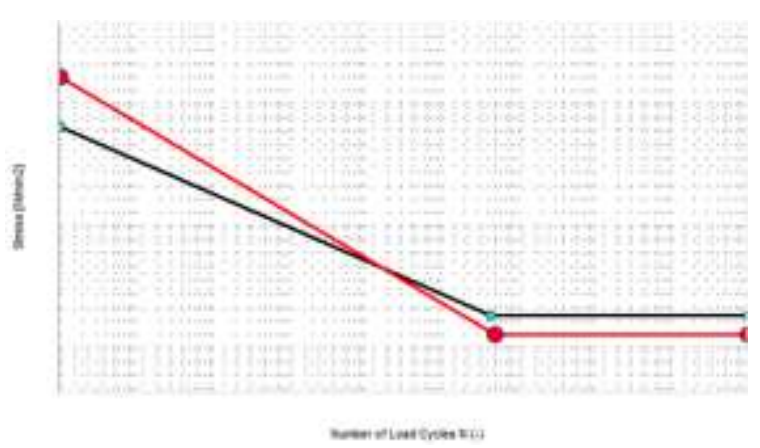

Figure 8. Previous and modified S-N curve.

\section{Iv. Results and Conclusion}

\section{A. Results}

As seen in Table 1 total damage value for the tank of 9 mm tank wall thickness is lower than $7 \mathrm{~mm}$ tank. Since the highest RMS and von Mises stress values occur at fully loaded tank, it is considered as the most critical condition. 
By increasing wall thickness about $37 \%$ and $28 \%$ improvement achieved in the first and second crack region respectively.

TABLE I. DAMAGE VALUES OF 7MM AND 9MM FUEL TANK FOR DIFFERENT FULLNESS RATES

\begin{tabular}{|c|l|l|l|l|}
\hline & \multicolumn{2}{|l|}{ 1st Crack Region } & \multicolumn{2}{l|}{ 2nd Crack Region } \\
\hline Fullness rate & $7 \mathrm{~mm}$ & $9 \mathrm{~mm}$ & $7 \mathrm{~mm}$ & $9 \mathrm{~mm}$ \\
\hline $4 / 4$ & 0.524 & 0.561 & 0.768 & 0.770 \\
\hline $3 / 4$ & 0.390 & 0.091 & 0.228 & 0.052 \\
\hline $2 / 4$ & 0.086 & 0.016 & 0.004 & 0.001 \\
\hline $1 / 4$ & 0.000 & 0.000 & 0.000 & 0.000 \\
\hline Total Damage & 1.000 & 0.668 & 1.000 & 0.823 \\
\hline
\end{tabular}

$9 \mathrm{~mm}$ tank also does not have any damage in the tests. However, with the targets set in the beginning of the project, decreasing the damage value further is important. Therefore, geometric optimization is conducted on the base model.

Damage values obtained from analysis of 4 different full tanks are given in Table 2 as a result of optimization procedure. In the first optimized tank, named as Opt-1, the damage is mainly decreased in the $1^{\text {st }}$ crack region, and an insignificant change is seen in the $2^{\text {nd }}$ crack region. However, in the second optimized tank (Opt-2), reductions in damages are significant for the both crack regions. For Opt-2, damage values are the smallest which indicates that optimization procedure on the fuel tank is successful in many ways. Third tank (Opt-3) is optimized with the advice of the manufacturer; however, damage results were not better. In final optimization based on Opt-2, damage values are optimized for both crack regions.

TABLE II. DAMAGE VALUES OF FULLY LOADED TANK MODELS

\begin{tabular}{|c|l|l|}
\hline & 1st Crack Region & 2nd Crack Region \\
\hline Opt-1 & 0.296 & 0.658 \\
\hline Opt-2 & 0.020 & 0.146 \\
\hline Opt-3 & 2.398 & 0.166 \\
\hline Opt-Final & 0.396 & 0.115 \\
\hline
\end{tabular}

The results of damage analysis of the final model are given for each fullness rate in Table 3. Optimization procedure from the beginning of the project yields $92 \%$ improvements in first crack region and nearly $88 \%$ in second region when $7 \mathrm{~mm}$ and Opt-Final tanks are compared.

TABLE III. DAMAGE VALUES OF FINAL MODEL

\begin{tabular}{|c|l|l|}
\hline \multicolumn{3}{|c|}{ Final Model } \\
\hline Fullness rate & 1st Crack Region & 2nd Crack Region \\
\hline $4 / 4$ & 0.069 & 0.115 \\
\hline $3 / 4$ & 0.011 & 0.010 \\
\hline $2 / 4$ & 0.000 & 0.000 \\
\hline $1 / 4$ & 0.000 & 0.000 \\
\hline Total Damage & 0.080 & 0.125 \\
\hline
\end{tabular}

All data are normalized.

\section{B. Conclusion}

Fatigue analysis of the polyethylene fuel tank is conducted to find damages on critical locations, and then these damage values are improved by the geometry optimization. The fuel inside the fuel tank is modeled with acoustic methodology. S-N curve obtained from 3 point bending tests is utilized as a tensile $\mathrm{S}-\mathrm{N}$ curve for FEMFAT. Optimization for decreasing total damage is conducted by a) increasing the wall thickness and $b$ ) the changing the shape of the tank. Even though increasing the wall thickness of the base model decreased the total damage value, better damage results, about $90 \%$ of improvements in total damage, are achieved by the geometry optimization which involves the changing the shape of the tank in critical regions.

\section{Acknowledgment}

This work, which is a collaboration project of MercedesBenz Turk A.S. and the Istanbul Technical University, is supported by the Ministry of Science, Industry and Technology of the Republic of Turkey, under the project number [0488.STZ.2013-2].

\section{References}

[1] K.D. Liehr, Plastic fuel tanks in the Federal Republic of Germany and in Europe, SAE Technical Paper Series, 880686, International Congress and Exposition Detroit, Michigan, 1988.

[2] V. V. S. Vytla,Y. Ando, Fluid structure interaction simulation of fuel tank sloshing, SAE International, 2013-01-0641,2013.

[3] K. Kamiya, Y. Yamaguchi, E. Vries, Simulation studies of sloshing in a fuel tank, SAE Technical Paper Series, 2002-01-0574,2002.

[4] Himeki, H., Kumagai, H., Morohoshi, K. "Fatigue Behavior Analysis and Durability Evaluation of Plastic Fuel Tank", SAE Technical Paper 2006-01-0782, 2006.

[5] Yay, K., ve Ereke M.İ. 2004: 'Bir Kamyon Gövdesinin Sanal Yol Verisi Yardımıyla S-N Yorulma Ömrü Analizi’ Otomotiv Teknolojileri Kongresi, Kongre Kitabı. Uludağ Üniversitesi Mühendislik Mimarlık Fakültesi Makine Mühendisliği Bölümü.

[6] Ansys User Manuel, Introduction to Acoustics, Acoustics ACTx R150.

[7] P. Hartwig, Multi-axial Fatigue Models for Composite Lightweight Structures (Master's thesis), 2013.

[8] J. Miodrag, "The Application of Some Approximate Solutions Of Stress And Strain Concentration For Life Estimation In The Low Cycle Fatigue Region," The Scientific Journal Facta Unıversitatis, Vol.1, No 8, 2001, pp. 1025 - 1032.

[9] Magna International Inc.,"Channel Max Training Notes”, 2015, pp. 165-178.

About Author (s):

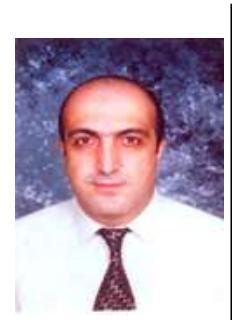

His work involves an interdisciplinary approach, combining mechanics of

materials and dynamics. Dr. Dogan's current research concentrates on vibration response and control of aerospace structural components under thermal and stochastic excitations. He is currently applying these ideas to smart materials such as FGMs,

PZTs, SMAs. This involves the development of mathematical methods for structural models. 